\title{
Relationship between Asthma and Rhinitis: Epidemiologic, Pathophysiologic, and Therapeutic Aspects
}

\author{
Celine Bergeron, MD, MSc; Qutayba Hamid, MD, PhD
}

\begin{abstract}
Over the last few years, the evidence of links between rhinitis and asthma has been strengthened. This has led to the introduction of the concept of united airway disease. Rhinitis and asthma appear to be interrelated at the epidemiologic level and at the pathophysiologic level. This article reviews current epidemiologic and pathophysiologic evidence of the relationship between rhinitis and asthma and discusses the effect of treatment of one site on the other site.
\end{abstract}

\section{Epidemiologic Links: Atopy}

Asthma and rhinitis are frequently associated with atopy with preferential sensitization to airborne allergens. Atopic diseases can manifest themselves at different sites on the body and can present as urticaria, allergic rhinitis, atopic dermatitis, conjunctivitis, food allergy, and asthma.

\section{Allergic Rhinitis and Asthma Prevalence}

Allergic rhinitis is an important health problem and affects up to $40 \%$ of the worldwide population. ${ }^{1,2}$ Its prevalence in the Canadian population is between 10 and $25 \% .^{1}$ Forty percent of allergic rhinitis patients have asthma, and as much as $94 \%$ of allergic asthma patients have allergic rhinitis. ${ }^{3-6}$ In Canada, the current prevalence of asthma is $8.4 \%{ }^{7}$ whereas worldwide prevalence varies from 1.6 to $37 \%{ }^{1}$

C. Bergeron, Q. Hamid-Meakins-Christie Laboratories, McGill University, Montreal, Quebec

Correspondence to: Qutayba Hamid, MD, PhD, MeakinsChristie Laboratories, McGill University, 3626 St-Urbain Street, Montreal, PQ H2X 2P2

\section{Allergic Rhinitis as a Risk Factor for Asthma}

Settipane and colleagues conducted a prospective study on a cohort consisting of young university students to determine the long-term risk factors for developing asthma and allergic rhinitis. ${ }^{8}$ The follow-up study 23 years later revealed that the incidence of asthma and allergic rhinitis increases with age. Furthermore, the presence of allergic rhinitis and positive results of allergen skin tests were shown to be important risk factors of asthma development. Patients with allergic rhinitis have a threefold greater chance of developing asthma. Interestingly, the relief of rhinitis symptoms over time correlates with the improvement of asthma symptoms. Patients with more severe and persistent rhinitis are at a higher risk of developing asthma. ${ }^{9}$ A strong association between perennial rhinitis and asthma in nonatopic subjects was also demonstrated in the European Community Respiratory Health Survey. ${ }^{10}$

To better understand the possible links between asthma and allergic rhinitis, the World Health Organization, through the Allergic Rhinitis and its Impact on Asthma (ARIA) program, examined the impact of allergic rhinitis on asthma. ${ }^{2}$ The ARIA study concluded that allergic rhinitis is a 
major chronic respiratory disease owing to its prevalence, impact on quality of life, impact on school and work performance and productivity, economic burden, and links to asthma. According to the ARIA study and previous observations, allergic and nonallergic rhinitis should be considered risk factors for asthma, along with other known risk factors.

\section{Physiopathologic Links}

The mucous membranes of both the upper and the lower airways are covered by a pseudostratified columnar ciliated epithelium with a continuous basement membrane. For this reason, these airways share a mucosal susceptibility to inhaled allergens. The obvious anatomic difference is the presence of smooth muscle in the lower airway as opposed to large venous sinusoids and prominent glands within the submucosa in the upper airway. The following section describes similarities and dissimilarities between rhinitis and asthma pathologies.

\section{Allergy}

Exposure to an allergen triggers an immediate reaction coordinated by mast cells and their mediators such as histamines, leukotrienes, and prostaglandins. In allergic rhinitis, this immediate reaction leads to nasal congestion and runny nose from an increase in vascular permeability. In asthma, the immediate reaction results in bronchospasm. Late-phase reaction occurs in both asthma and rhinitis following allergen exposure and is mainly triggered by $\mathrm{CD} 4^{+} \mathrm{T}$ cells. ${ }^{11}$ Allergic rhinitis and asthma share many pathologic features. In fact, the same profile of inflammation, mediators, and adhesion molecules can be observed in upper- and lower-airway allergic diseases. There is a common cellular inflammation pattern characterized by eosinophil, mast-cell, and $\mathrm{CD}^{+}{ }^{+} \mathrm{T}$-cell infiltration..$^{12,13}$ Mediators (including histamine; cysteinyl leukotrienes; interleukin [IL]-4, IL-5, IL-13; regulated on activation, normal T-cell expressed and secreted [RANTES] chemokine; and eotaxin) are expressed in both upper and lower airways. ${ }^{14,15}$ Although the initial inflammation induced by allergens is similar in upper and lower airways, the long-term structural consequences differ. The respiratory epithelium is disrupted in bronchial asthma whereas only minimal epithelial shedding is observed in allergic rhinitis. The subepithelial basement membrane is thickened with an increased amount of collagen deposition in asthma. Although this thickening can also occur in the upper airway in rhinitis, the extent of this process is less than that seen in the lower airway in asthma. ${ }^{16}$

\section{Allergic Rhinitis, Airway Hyperresponsiveness, and Asthma}

It is well established that $40 \%$ of nonasthmatic patients with allergic rhinitis have increased airway hyperresponsiveness. ${ }^{17}$ Allergen nasal challenge or seasonal allergen exposure leads to increased airway hyperresponsiveness in rhinitis patients. ${ }^{18,19}$ The number of eosinophils in the sputum correlates with nonspecific airway hyperresponsiveness not only in asthma but also in allergic seasonal rhinitis. ${ }^{20}$ Nasal eosinophilia correlates with bronchial reactivity in allergic children who have both asthma and rhinitis. ${ }^{21}$ Gaga and colleagues found eosinophilic infiltration in the nasal mucosa of asthmatic patients even in the absence of rhinitis. ${ }^{22}$ The relationship between nasal allergy and asymptomatic airway hyperresponsiveness supports the concept of one airway, one disease.

\section{Nonallergic Rhinitis and Nonallergic Asthma}

An inflammatory pattern has been characterized in asthmatic children suffering from allergic rhinitis and in those with nonallergic rhinitis. ${ }^{23}$ Surprisingly, both groups have a typical T-helper 2 (Th2) cytokine inflammatory pattern as measured in rhino-sinusal lavage. Nonatopic or intrinsic asthmatic patients have an inflammatory pattern similar to that of atopic asthma patients although this nonatopic group has been less extensively studied. Increased levels of IL-3, IL-4, IL-5, 
granulocyte-macrophage colony-stimulating factor (GM-CSF), and eosinophils were found in endobronchial biopsy specimens from nonatopic asthma patients. ${ }^{24-27}$ Even in the absence of an allergic process, rhinitis and asthma share similar inflammatory profiles, linking both diseases. Epidemiologic studies are consistent with these findings, as nonatopic rhinitis has also been reported to be an independent risk factor for developing asthma. ${ }^{2}$

\section{Allergic Challenge}

To better understand the allergen relationship between upper and lower airways, many studies have examined this paradigm, using nasal or bronchial allergen challenge and observing its effect on the opposite site of the airway.

\section{Effect of Nasal Allergen Exposure on Lower Airways}

Nasal allergen challenge increases eosinophils and adhesion molecules in both nasal and bronchial biopsy specimens from nonasthmatic patients with rhinitis. ${ }^{28}$ Chakir and colleagues also showed that natural pollen exposure is associated with an increase in lymphocyte numbers, eosinophil recruitment, and IL-5 expression in the bronchial mucosa of nonasthmatic persons with allergic rhinitis. ${ }^{29}$ In another study, Chakir and colleagues showed that allergic nonasthmatic patients with seasonal pollen-induced rhinitis had airway pathologic changes (as seen in bronchial biopsy specimens) similar to those observed in asthmatic patients. ${ }^{30}$ These changes consisted of cellular infiltration, mucosal edema, increased epithelial desquamation, and focal basement-membrane thickening.

\section{Effect of Lower-Airway Allergen Exposure on Nasal Mucosa}

Segmental bronchial allergen challenge in nonasthmatic allergic rhinitis patients leads to a decrease in nasal peak inspiratory flow and a concomitant increase in nasal symptomatology. ${ }^{31}$ It also increases eosinophils, eotaxin-positive cells, and IL-5 expression in nasal mucosa biopsy specimens ${ }^{31}$ and decreases mast cells. ${ }^{32}$ The decrease in the number of mast cells is attributed to a higher rate of degranulation.

\section{Mechanisms That Might Explain the Link between Upper and Lower Airways}

A number of mechanisms have been suggested to explain the link between upper and lower airways and the concept of united airway disease. They include genetic factors, an anatomic link between upper and lower airways, neural interaction between the nose and the lower airway, and mediator- or inflammatory-cell circulation. Inflammatory mediators can reach the lower airway from the upper airway through the airway passages. They might also be able to reach the lower airway through the blood. A number of these mediators, such as histamine, cysteinyl leukotrienes, and some cytokines, have the ability to spill over into the systemic circulation. However, very few data support this concept, and most of the cytokines have a very short halflife and do not act in an endocrine fashion. Inman $^{33}$ and Denburg ${ }^{34}$ suggested that inflammatory mediators such as IL-5 and GM-CSF can travel from the lung to the bone marrow, where they could stimulate the progenitors' release to the circulation and to the target organs. We have shown that after antigen challenge, there is an increase in IL5 -producing $\mathrm{T}$ cells in the bone marrow and an increase in high-affinity IL-5 receptor, which is associated with an elevated number of eosinophil progenitors. ${ }^{35,36}$ Recently, we showed that this process is most likely due to retrograde migration of antigen-specific T cells from the airways to the bone marrow, where antigen-specific $\mathrm{T}$ cells can produce a number of cytokines and help to release and differentiate the progenitor cells ${ }^{37}$ Progenitor cells can be found along the entire airway in atopic individuals ${ }^{38}$ and can differentiate into mature eosinophils in response to local antigen challenge $^{39}$ (Figure 1). 


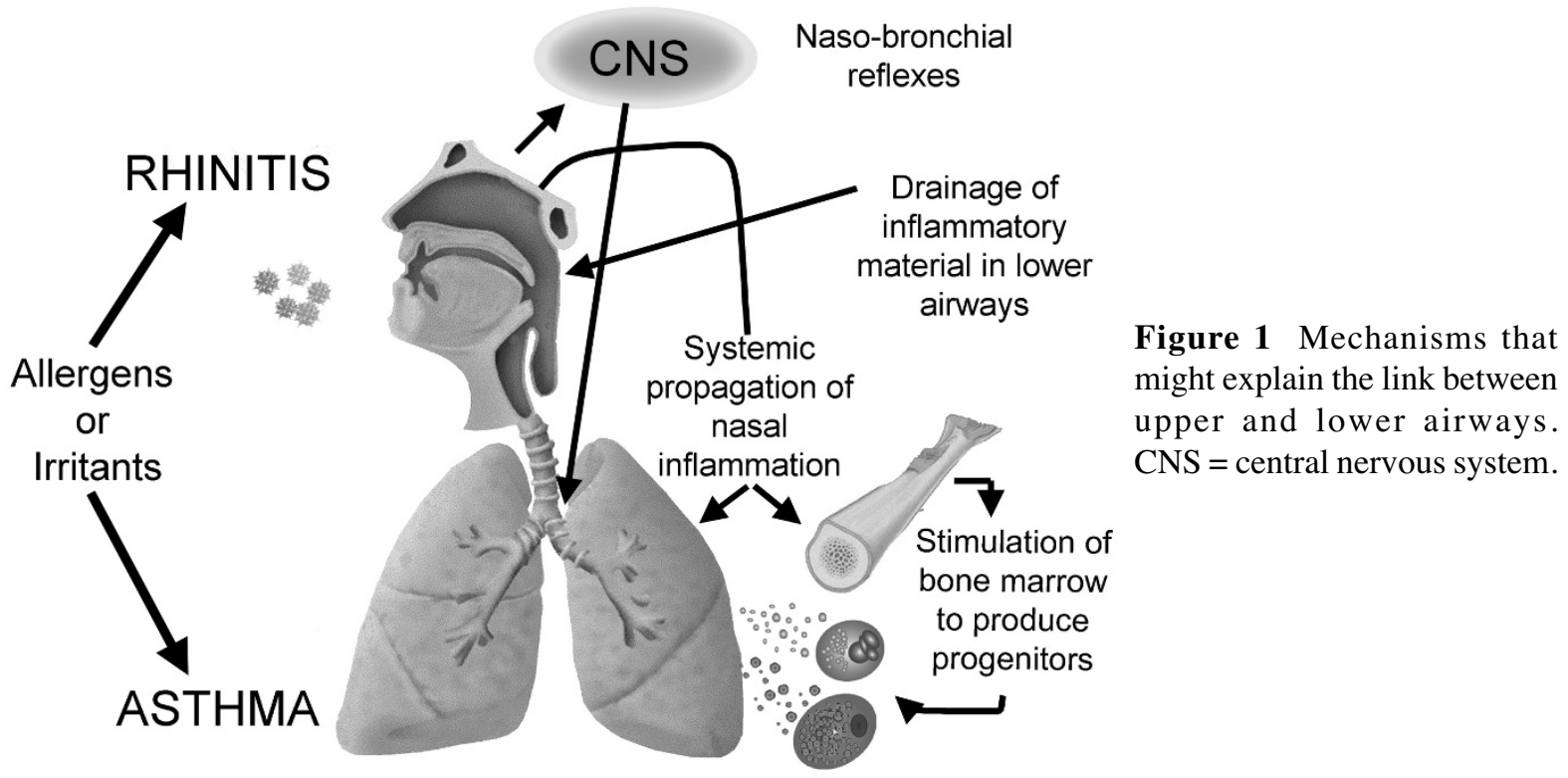

\section{Treatment of Asthma and Allergic Rhinitis}

As mentioned earlier, the pathophysiology of allergic rhinitis is very similar to that of allergic asthma, and the responses of the two conditions to pharmacologic and immunologic interventions are comparable. The most commonly used drugs for both conditions are corticosteroids. However, other anti-inflammatory drugs with systemic effects have been recently introduced for the management of both diseases.

\section{Effect of Rhinitis Treatment on Asthma}

A recent meta-analysis of asthma outcomes and the treatment of rhinitis with intranasal corticosteroids failed to show any significant improvement in asthma symptoms or in lung function ${ }^{40}$ although a trend in favor of intranasal corticosteroids was reported. In nonasthmatic children with allergic rhinitis, intranasal corticosteroids significantly improved airway hyperresponsiveness to methacholine but had no effect on asthma symptoms. ${ }^{41}$ Corren and colleagues reported that intranasal corticosteroids prevent the increase of bronchial responsiveness associated with seasonal pollen exposure in allergic rhinitis patients with asthma. ${ }^{18}$ Other anti-inflammatory drugs (montelukast and cetirizine), when used for rhinitis patients, have also been reported to improve asthma symptoms and to decrease the use of $\beta_{2}$ agonists. ${ }^{42}$ Recent studies have reported a decrease in asthma exacerbation in patients with concomitant allergic rhinitis when these patients received any kind of rhinitis treatment. ${ }^{43,44}$ Cetirizine, an antihistamine, has shown effectiveness in relieving upper- and lower-airway symptoms in patients suffering from concomitant allergic rhinitis and asthma ${ }^{45}$ Cetirizine was found to be protective against late bronchial hyperresponsiveness that follows nasal allergen challenge in patients with allergic rhinitis. ${ }^{46}$ Combined therapy with montelukast and cetirizine for asthmatic patients with seasonal allergic rhinitis lessens the need for a rescue inhaler and improves lung function and asthma symptom score to the same extent as does inhaled budesonide combined with intranasal budesonide. ${ }^{47}$

\section{Effect of Asthma Treatment on Rhinitis}

Greiff and colleagues treated nonasthmatic allergic rhinitis patients with inhaled corticosteroids during pollen season. They found an inhibition of the increase of eosinophils in blood and nasal tissues that is usually observed in pollen season. ${ }^{48}$ The patients who received inhaled budesonide had significantly milder nasal symptoms. In a recent clinical study, asthmatic individuals with nasal 
polyposis treated with montelukast had a $70 \%$ improvement of nasal symptoms and a $60 \%$ to $90 \%$ improvement in asthma clinical score. ${ }^{49}$ In a study comparing treatment with montelukast alone to treatment with inhaled and intranasal corticosteroids in patients with allergic rhinitis and in patients with asthma, only the group treated with corticosteroids showed a significant reduction in nasal nitric oxide and in nasal peak flow, whereas both treatments were efficient in decreasing rhinitis symptoms..$^{50}$

\section{Immunotherapy}

Immunotherapy is reserved for patients with moderately severe allergic rhinitis. Immunotherapy reduces inflammatory-cell recruitment and activation as well as the secretion of mediators. ${ }^{2}$ In a group of allergic rhinitis patients with asthma, immunotherapy improved methacholine hyperreactivity and quality of life and reduced seasonal asthma symptoms.$^{51}$ Reducing the allergen sensitivity not only leads to relief of rhinitis but also helps control asthma (although less effectively).

\section{Conclusion}

It is important to carefully assess the upper airways in asthmatic patients and the lower airways in patients with allergic rhinitis. Allergic rhinitis is an important risk factor for developing asthma and is also an important cause of nonoptimal control of asthma. Links between upper- and lower-airway diseases exist through inflammatory mediators, but other mechanisms, such as mouth breathing and postnasal drip, can contribute. Many therapeutic options are currently available although corticosteroids remain the most effective anti-inflammatory drugs. Antileukotrienes have beneficial effects on rhinitis and asthma because they work through a systemic effect. Our common approach to the treatment of asthma and rhinitis needs to be revised to prevent the expression of the asthma phenotype in individuals who have rhinitis and to achieve better control of asthma in patients who already have both rhinitis and asthma.

\section{References}

1. Strachan D, Sibbald B, Weiland S, et al. Worldwide variations in prevalence of symptoms of allergic rhinoconjunctivitis in children: the International Study of Asthma and Allergies in Childhood (ISAAC). Pediatr Allergy Immunol 1997;8:161-76.

2. Bousquet J, Van Cauwenberge P, Khaltaev N. Allergic rhinitis and its impact on asthma. $\mathrm{J}$ Allergy Clin Immunol 2001;108:S147-334.

3. Yawn BP, Yunginger JW, Wollan PC, et al. Allergic rhinitis in Rochester, Minnesota residents with asthma: frequency and impact on health care charges. J Allergy Clin Immunol 1999;103:54-9.

4. Togias AG. Systemic immunologic and inflammatory aspects of allergic rhinitis. J Allergy Clin Immunol 2000;106:S247-50.

5. Vinuya RZ. Upper airway disorders and asthma: a syndrome of airway inflammation. Ann Allergy Asthma Immunol 2002;88:8-15.

6. Leynaert B, Neukirch F, Demoly P, Bousquet J. Epidemiologic evidence for asthma and rhinitis comorbidity. J Allergy Clin Immunol 2000;106:S201-5.

7. Chen Y, Johansen H. Population aged 12 and over who report that they have been diagnosed by a health professional as having asthma [tables 104-0001 and 105-0001]. Statistics Canada, CANSIM; report number 2004002: 2004; 16(2).

8. Settipane RJ, Hagy GW, Settipane GA. Longterm risk factors for developing asthma and allergic rhinitis: a 23-year follow-up study of college students. Allergy Proc 1994;15:21-5.

9. Guerra S, Sherrill DL, Martinez FD, Barbee RA. Rhinitis as an independent risk factor for adultonset asthma. J Allergy Clin Immunol 2002;109:419-25.

10. Leynaert B, Bousquet J, Neukirch C, et al. Perennial rhinitis: an independent risk factor for asthma in nonatopic subjects: results from the European Community Respiratory Health Survey. J Allergy Clin Immunol 1999;104:301-4.

11. Durham SR. Mechanisms of mucosal inflammation in the nose and lungs. Clin Exp Allergy 1998;28 Suppl 2:11-6.

12. Bradley BL, Azzawi M, Jacobson M, et al. Eosinophils, T-lymphocytes, mast cells, neutrophils, and macrophages in bronchial biopsy specimens from atopic subjects with asthma: 
comparison with biopsy specimens from atopic subjects without asthma and normal control subjects and relationship to bronchial hyperresponsiveness. J Allergy Clin Immunol 1991;88:661-74.

13. Varga EM, Jacobson MR, Till SJ, et al. Cellular infiltration and cytokine mRNA expression in perennial allergic rhinitis. Allergy 1999;54:338-45.

14. KleinJan A, Dijkstra MD, Boks SS, et al. Increase in IL-8, IL-10, IL-13, and RANTES mRNA levels (in situ hybridization) in the nasal mucosa after nasal allergen provocation. J Allergy Clin Immunol 1999;103:441-50.

15. Nag S, Lamkhioued B, Renzi PM. Interleukin2-induced increased airway responsiveness and lung Th2 cytokine expression occur after antigen challenge through the leukotriene pathway. Am J Respir Crit Care Med 2002;165:1540-5.

16. Bousquet J, Jacquot W, Vignola AM, et al. Allergic rhinitis: a disease remodeling the upper airways? J Allergy Clin Immunol 2004;113:43-9.

17. Ramsdale EH, Morris MM, Roberts RS, Hargreave FE. Asymptomatic bronchial hyperresponsiveness in rhinitis. J Allergy Clin Immunol 1985;75:573-7.

18. Corren J, Adinoff AD, Buchmeier AD, Irvin CG. Nasal beclomethasone prevents the seasonal increase in bronchial responsiveness in patients with allergic rhinitis and asthma. J Allergy Clin Immunol 1992;90:250-6.

19. Corren J, Adinoff AD, Irvin CG. Changes in bronchial responsiveness following nasal provocation with allergen. J Allergy Clin Immunol 1992;89:611-8.

20. Foresi A, Leone C, Pelucchi A, et al. Eosinophils, mast cells, and basophils in induced sputum from patients with seasonal allergic rhinitis and perennial asthma: relationship to methacholine responsiveness. J Allergy Clin Immunol 1997;100:58-64.

21. Sale R, Silvestri M, Battistini E, et al. Nasal inflammation and bronchial reactivity to methacholine in atopic children with respiratory symptoms. Allergy 2003;58:1171-5.

22. Gaga M, Lambrou P, Papageorgiou N, et al. Eosinophils are a feature of upper and lower airway pathology in non-atopic asthma, irrespective of the presence of rhinitis. Clin Exp Allergy 2000;30:663-9.

23. Riccio AM, Tosca MA, Cosentino C, et al. Cytokine pattern in allergic and non-allergic chronic rhinosinusitis in asthmatic children. Clin Exp Allergy 2002;32:422-6.

24. Yasruel Z, Humbert M, Kotsimbos TC, et al. Membrane-bound and soluble alpha IL-5 receptor mRNA in the bronchial mucosa of atopic and nonatopic asthmatics. Am J Respir Crit Care Med 1997;155:1413-8.

25. Ulrik CS. Peripheral eosinophil counts as a marker of disease activity in intrinsic and extrinsic asthma. Clin Exp Allergy 1995;25:820-7.

26. Humbert M. Airways inflammation in asthma and chronic bronchitis. Clin Exp Allergy 1996;26:735-7.

27. Humbert M, Corrigan CJ, Kimmitt P, et al. Relationship between IL-4 and IL-5 mRNA expression and disease severity in atopic asthma. Am J Respir Crit Care Med 1997;156:704-8.

28. Braunstahl GJ, Overbeek SE, Kleinjan A, et al. Nasal allergen provocation induces adhesion molecule expression and tissue eosinophilia in upper and lower airways. J Allergy Clin Immunol 2001;107:469-76.

29. Chakir J, Laviolette M, Turcotte H, et al. Cytokine expression in the lower airways of nonasthmatic subjects with allergic rhinitis: influence of natural allergen exposure. J Allergy Clin Immunol 2000;106:904-10.

30. Chakir J, Laviolette M, Boutet M, et al. Lower airways remodeling in nonasthmatic subjects with allergic rhinitis. Lab Invest 1996;75:735-44.

31. Braunstahl GJ, Kleinjan A, Overbeek SE, et al. Segmental bronchial provocation induces nasal inflammation in allergic rhinitis patients. Am J Respir Crit Care Med 2000;161:2051-7.

32. Braunstahl GJ, Overbeek SE, Fokkens WJ, et al. Segmental bronchoprovocation in allergic rhinitis patients affects mast cell and basophil numbers in nasal and bronchial mucosa. Am J Respir Crit Care Med 2001;164:858-65.

33. Inman MD. Bone marrow events in animal models of allergic inflammation and hyperresponsiveness. J Allergy Clin Immunol 2000;106:S235-41.

34. Denburg J. The bone marrow and airway inflammation: evidence for allergy as a systemic disease. Clin Exp Allergy Review 2003;3:23-7.

35. Sehmi R, Wood LJ, Watson R, et al. Allergeninduced increases in IL-5 receptor alpha-subunit expression on bone marrow-derived CD34+ cells from asthmatic subjects. A novel marker of 
progenitor cell commitment towards eosinophilic differentiation. J Clin Invest 1997;100:2466-75.

36. Wood LJ, Sehmi R, Dorman S, et al. Allergeninduced increases in bone marrow $\mathrm{T}$ lymphocytes and interleukin-5 expression in subjects with asthma. Am J Respir Crit Care Med 2002; 166:883-9.

37. Isogai S, Miyata S, Taha R, et al. CD4 T cells migrate from airway to bone marrow after antigen inhalation in rats. J Allergy Clin Immunol 2004;113:455-61.

38. Robinson DS, North J, Zeibecoglou K, et al. Eosinophil development and bone marrow and tissue eosinophils in atopic asthma. Int Arch Allergy Immunol 1999;118:98-100.

39. Cameron L, Hamid Q, Wright E, et al. Local synthesis of epsilon germline gene transcripts, IL-4, and IL-13 in allergic nasal mucosa after ex vivo allergen exposure. J Allergy Clin Immunol 2000;106:46-52.

40. Taramarcaz P, Gibson P. Intranasal corticosteroids for asthma control in people with coexisting asthma and rhinitis. Cochrane Database Syst Rev 2003;4:CD003570.

41. Watson WT, Becker AB, Simons FE. Treatment of allergic rhinitis with intranasal corticosteroids in patients with mild asthma: effect on lower airway responsiveness. J Allergy Clin Immunol 1993;91:97-101.

42. Wilson AM, Orr LC, Sims EJ, Lipworth BJ. Effects of monotherapy with intra-nasal corticosteroid or combined oral histamine and leukotriene receptor antagonists in seasonal allergic rhinitis. Clin Exp Allergy 2001;31:61-8.

43. Crystal-Peters J, Neslusan C, Crown WH, Torres A. Treating allergic rhinitis in patients with comorbid asthma: the risk of asthma-related hospitalizations and emergency department visits. J Allergy Clin Immunol 2002;109:57-62.

44. Adams RJ, Fuhlbrigge AL, Finkelstein JA, Weiss ST. Intranasal steroids and the risk of emergency department visits for asthma. J Allergy Clin Immunol 2002;109:636-42.

45. Grant JA, Nicodemus CF, Findlay SR, et al. Cetirizine in patients with seasonal rhinitis and concomitant asthma: prospective, randomized, placebo-controlled trial. J Allergy Clin Immunol 1995;95:923-32.

46. Aubier M, Neukirch C, Peiffer C, Melac M. Effect of cetirizine on bronchial hyperresponsiveness in patients with seasonal allergic rhinitis and asthma. Allergy 2001;56:35-42.

47. Wilson AM, Orr LC, Sims EJ, et al. Antiasthmatic effects of mediator blockade versus topical corticosteroids in allergic rhinitis and asthma. Am J Respir Crit Care Med 2000;162:1297-301.

48. Greiff L, Andersson M, Svensson C, et al. Effects of orally inhaled budesonide in seasonal allergic rhinitis. Eur Respir J 1998;11:1268-73.

49. Ragab S, Parikh A, Darby YC, Scadding GK. An open audit of montelukast, a leukotriene receptor antagonist, in nasal polyposis associated with asthma. Clin Exp Allergy 2001;31:1385-91.

50. Wilson AM, Dempsey OJ, Sims EJ, Lipworth BJ. A comparison of topical budesonide and oral montelukast in seasonal allergic rhinitis and asthma. Clin Exp Allergy 2001;31:616-24.

51. Walker SM, Pajno GB, Lima MT, et al. Grass pollen immunotherapy for seasonal rhinitis and asthma: a randomized, controlled trial. J Allergy Clin Immunol 2001;107:87-93. 